\title{
Ilustración de las leyendas de la ciudad Riobamba, como estrategia para el fortalecimiento de la identidad cultural en la población infantil.
}

\author{
Illustration of the legends of the city Riobamba, as a strategy for \\ strengthening the cultural identity in the child population.
}

\begin{abstract}
Rosa Belén Ramos Jiménez. ${ }^{1}$, Edison Fernando Martínez Espinoza. ${ }^{2}$, Fabián Alfonso Calderón Cruz. ${ }^{3} \&$ Miriam Elizabeth Erazo Rodríguez. ${ }^{4}$
\end{abstract}

\begin{abstract}
.
Introduction This research corresponds to the third phase of the research project "Illustration of Riobamba legends as a strategy for strengthening identity in the child population of the Riobamba canton.", Objective Which objective to develop illustrations of the legends of the city of Riobamba. For this, a general investigation was carried out which the historical, social and cultural context of each legend was established. Methodology After this, a detailed study of each legend was carried out, which consisted of an investigation in which information was investigated in various sources: a bibliographic investigation in which different versions of the legends of various authors were obtained; a field investigation in which visits were made to the environments where the events are believed to have taken place; Also, interviews were conducted with citizens from the places, and with expert historians of the city who provided precise and detailed data. All information was recorded in technical files, this process was replicated in each of the legends. Results Once the material was obtained, the illustrations were created, starting with the reading and understanding of the legend, later, the fragmentation of the

\footnotetext{
${ }^{1}$ Escuela Superior Politécnica de Chimborazo, Carrera de Diseño Gráfico, Riobamba, Ecuador, rosa.ramos@espoch.edu.ec, https://orcid.org/0000-0001-5080-6123

2 Escuela Superior Politécnica de Chimborazo, Carrera de Diseño Gráfico, Riobamba, Ecuador, edison.martinez@espoch.edu.ec. https://orcid.org/0000-0002-5320-9460

${ }^{3}$ Escuela Superior Politécnica de Chimborazo, Carrera de Diseño Gráfico, Riobamba, Ecuador, fabian.calderon@espoch.edu.ec. https://orcid.org/0000-0001-5472-3405

4 Universidad Nacional de Chimborazo, Carrera de Comunicación, Riobamba, Ecuador, miriamerazo@unach.edu.ec, https://orcid.org/0000-0003-1569-7245
} 
story to establish the visual narrative and the choice of the appropriate narrative elements to tell the story and finally the development of illustrations applying digital illustration techniques. As a result, 6 illustrated legends were obtained.

Keywords: illustration, design characters, legends, culture, heritage.

\section{Resumen}

Introducción La presente investigación corresponde a la tercera fase del proyecto de investigación "Ilustración de leyendas riobambeñas como estrategia para el fortalecimiento de la identidad en la población infantil del cantón Riobamba.”, Objetivo la cual tiene como objetivo, el desarrollo de ilustraciones de las leyendas de la ciudad de Riobamba. Metodología Para ello, se llevó a cabo una investigación general a partir de la cual se estableció el contexto histórico, social y cultural de cada leyenda. Posterior a esto, se realizó un estudio minucioso de cada leyenda que consistió en una investigación en la cual se indagó en varias fuentes información: una investigación bibliográfica en la cual se obtuvo distintas versiones de las leyendas de varios autores; una investigación de campo en la que se realizaron visitas a los entornos donde se cree se llevaron a cabo los sucesos; también, se realizaron entrevistas a ciudadanos oriundos de los lugares, y a historiadores expertos de la ciudad quienes aportaron datos precisos y detallados. Toda esta información fue registrada en fichas técnicas, este proceso se replicó en cada una de las leyendas. Resultados Una vez se obtuvo el material, se procedió a la creación de las ilustraciones, empezando por la lectura y entendimiento de la leyenda, posteriormente, la fragmentación de la historia para establecer la narrativa visual y la elección de los elementos narrativos adecuados para contar la historia y finalmente el desarrollo de las ilustraciones aplicando técnicas de ilustración digital. Como resultado se obtuvieron 6 leyendas ilustradas.

Palabras Claves: ilustración, leyendas, diseño de personajes, cultura, patrimonio.

\section{Introducción}

Por mucho tiempo, la ilustración acompañada a la literatura infantil, siendo las imágenes un factor determinante en la compresión de la lectura, que además de ser un recurso estético capaz de estimular la imaginación, manteniendo así el interés del niño en la historia. En los libros infantiles, el poder de la ilustración va más allá de adornar el texto, la ilustración puede llegar a ser tan efectiva que puede contar la historia por si sola, lo que lleva a pensar que la ilustración es tan importante como el texto que acompañan.

Así, Verónica Uribe y Marianne Delon mencionan, "Las imágenes y la concepción gráfica son de gran importancia en un libro para niños. En el aprendizaje de la lectura y en la consolidación de hábitos de lectura, las imágenes juegan un papel interesante de apoyo, motivación y apresto a la lectura. No deben ser simples adornos del libro ni debemos considerar que simplemente hacen al libro más bonito. Las imágenes constituyen por sí mismas un lenguaje de fácil 
aprehensión por parte de los niños, que pueden tener tanta o más importancia que el lenguaje escrito." (Uribe, V., Delon, M., 1983, p. 27).

Del mismo modo, Vernon Lord, en su ponencia titulada " "Algunos aspectos que el ilustrador debe tener en cuenta en el proceso de creación de libros ilustrados para niños»" del IV Simposio Internacional Catalònia d'Il·lustració sobre las propiedades educativas de la ilustración menciona, "La ilustración es un arte instructivo: ensancha y enriquece nuestro conocimiento visual y la percepción de las cosas. A menudo interpreta y complementa un texto o clarifica visualmente las cosas que no se dejan expresar con palabras. Las ilustraciones pueden explicar el significado mediante esquemas o diagramas o exponer conceptos imposibles de comprender mediante una manera convencional. Pueden reconstruir el pasado, reflejar el presente, imaginar el futuro o mostrar situaciones imposibles en un mundo real o irreal." (Vernon, L., 1997, p. 168).

Consientes ya de las propiedades educativas de la ilustración en la población infantil, es necesario subrayar la importancia de la educación cultural en la formación integral de los niños, ya que, de esta se deprenden las creencias, las costumbres, los valores, ritos y espiritualidades, entre otros rasgos transmitidos de generación en generación y que formaran parte de identidad cultural de los niños. Como sugiere la última reforma educativa del Ecuador, con respecto a la educación cultural y artística, esta pretende garantizar el aprendizaje desde temprana edad en torno a tres dimensiones: personal y afectiva-emocional (el yo: la identidad); social y relacional (el encuentro con otros: la alteridad); y simbólica y cognitiva (el entorno: espacio, tiempo y objetos). Así las leyendas apoyadas en las ilustraciones le permitirán al niño conectar con cada dimensión; emocional y afectivamente al conocer las leyendas y su origen, social y relacionalmente al conocer los personajes, a través del texto su historia y a través de las ilustraciones dándoles un rostro; simbólica y cognitivamente, al observar los escenarios y objetos inmersos en su propio entorno, incluso la propia jerga y demás recursos visuales y lingüísticos incluidos en el desarrollo de cada leyenda, que permiten que el niño se identifique y conecte con cada historia.

Eco (1998), argumenta que cuando se pierde la memoria se pierde la identidad, por eso las sociedades cuentan con sistemas que permiten mantener y comunicar la memoria: "nuestra identidad se fundamenta en la larga memoria colectiva. (Eco, 1998:263). En el mismo sentido, Edward Said asegura, "ninguna identidad cultural aparece de la nada; todas son construidas de modo colectivo sobre las bases de la experiencia, la memoria y la tradición. (Said, 2001:3).

Margarita Luciano y Eleanor Grimaldi (1998), “a partir de la literatura infantil se pueden conseguir numerosos logros y se pueden desglosar en los siguientes: el desarrollo artístico, el desarrollo de los sentimientos, el desarrollo de los valores humanos y el desarrollo de los valores culturales". Por otro lado, Führer, establece que el ilustrador debe mantener un lenguaje tal que sea comprensible para el niño. Buscar una identificación de la historia (personajes, ambiente, etc.). 
De aquí, el objetivo de crear leyendas ilustradas significativas, capaces de contar, conmover e impregnarse en la mente de los niños. Para ello, se debe considerar la función de la ilustración, en este caso, la de contar una historia a través de una secuencia de imágenes, mismas que contienen una serie de signos que se combinan, dando lugar a la narrativa y la interpretación.

Así, para conseguir encajar el texto y la imagen, es necesario cumplir con algunos aspectos que determinará la efectividad de la imagen; la iconicidad que se refiere al parecido de la imagen con la realidad representada, en donde los seres, objetos, o escenarios representados, deben ser reconocidos fácilmente por los niños, tanto por su forma como por aquellos rasgos que los ubican dentro de una contexto social y cultural, de tal manera que el niño se identifique y conecte con la historia a nivel visual y emocional. Por otro lado, construir la narrativa visual, que se refiere a la capacidad que tiene la totalidad imagen para contar la historia, es decir se conjugan los elementos visuales: plásticos, compositivos y conceptuales, facilitando la conducción del mensaje visual, de manera que el niño logre relacionarlos y en consecuencia interprete la historia.

Así, el desarrollo de ilustraciones de las leyendas riobambeñas brinda un espacio de formación e interacción con los saberes, que motiva al niño a apropiarse de estas tradiciones creando lazos entre lo tradicional y lo contemporáneo, entre lo que leen y lo que ven, entre lo que desconocen y reconocen. Además, la ilustración de las leyendas servirá como un registro para mantener y comunicar aquellos mitos y leyendas que forman parte fundamental de la herencia de sus antepasados y que hasta ahora se han transmitido únicamente de forma oral. Su correcta materialización y difusión, aseguran su perdurabilidad en el tiempo y en la memoria colectiva de las futuras generaciones de los ciudadanos riobambeños.

\section{Metodología.}

Bruce Archer (1995), menciona "A view of the nature of design research señala que la " Investigación en diseño es una indagación sistemática cuyo objetivo es el conocimiento de, o en, la encarnación de la configuración, composición, estructura, propósito, valor y significado en las cosas y sistemas artificiales".

De esta visión, se propone un proceso que tuvo como principal objetivo la selección y combinación de los elementos visuales para dar lugar a una narrativa visual efectiva. Para ello, se considera que el lenguaje visual utiliza diferentes elementos narrativos, los cuales se pueden dividir en 3 grupos:

Elementos plásticos, aquellos determinan la apariencia de la ilustración como: el tono, la forma, la perspectiva, la iluminación; Elementos compositivos, que se refieren a la organización de los recursos visuales dentro del espacio del formato, se relaciona con el recorrido de lectura y con la posición en la que se quiere ubicar al lector dentro de una escena. el tamaño, la posición, ángulos, planos, encuadres; Elementos conceptuales, que 
se refieren a aquellos que establecerán la relación entre la imagen y el texto como: personajes, escenarios, ambientes, objetos, acciones, entre otros.

\section{Proceso de creación de las ilustraciones}

\section{Lectura, comprensión y segmentación de la historia.}

Wigan (2007), en su libro titulado "Secuential Images", cita "Una lectura y relectura completa de la historia o el guion y la toma de notas complementarán la investigación visual." (Wigan, M., 2007, p. 22). Así mismo asegura "La selección y edición de imágenes es crucial, es cuestión de elegir imágenes que capturan momentos esenciales y clímax que resaltan y comunican la narrativa."

Por lo que, una vez dominada la historia, se realizó la segmentación de la misma con la cual se obtuvo como resultado una secuencia de imágenes repartidas espacial y cronológicamente.

\section{Documentación.}

Para ilustrar se requiere de elementos inspiradores. Los datos, los referentes y los recursos compilados son fuentes de inspiración.

Wigan (2007), las narrativas se pueden establecer en muchos contextos (históricos, contemporáneos, mitológicos y futuristas), por lo que una investigación adecuada mejorará el realismo, el detalle y la continuidad de sus imágenes.

Así, para establecer los elementos visuales encargados de contar las historias, fue necesario ubicarse en el contexto histórico, social y cultural de cada leyenda, en primer lugar, se realizó un estudio general de cada leyenda, en el cual se indagó en varias fuentes información; investigación bibliográfica, se obtuvieron versiones de las leyendas de varios autores, investigación de campo en la que se realizaron visitas a los entornos donde se cree se llevaron a acabo los sucesos y se realizaron entrevistas a ciudadanos oriundos de los lugares, en especial adultos mayores. Para concluir este estudio, se llevaron a cabo entrevistas a historiadores expertos de la ciudad quienes aportaron datos precisos y detallados, así, se establecieron aspectos generales de cada leyenda, tales como: personajes principales, escenarios, época, entre otros.

A continuación, se observa el modelo la ficha establecida para el registro de la información de cada leyenda.

\section{Tabla 1,}

Modelo ficha de la leyenda

1. NOMBRE DE LA LEYENDA:

2. LUGAR DE LA LEYENDA: 


\section{DESCRIPCIÓN / RELATO DE LA LEYENDA:}

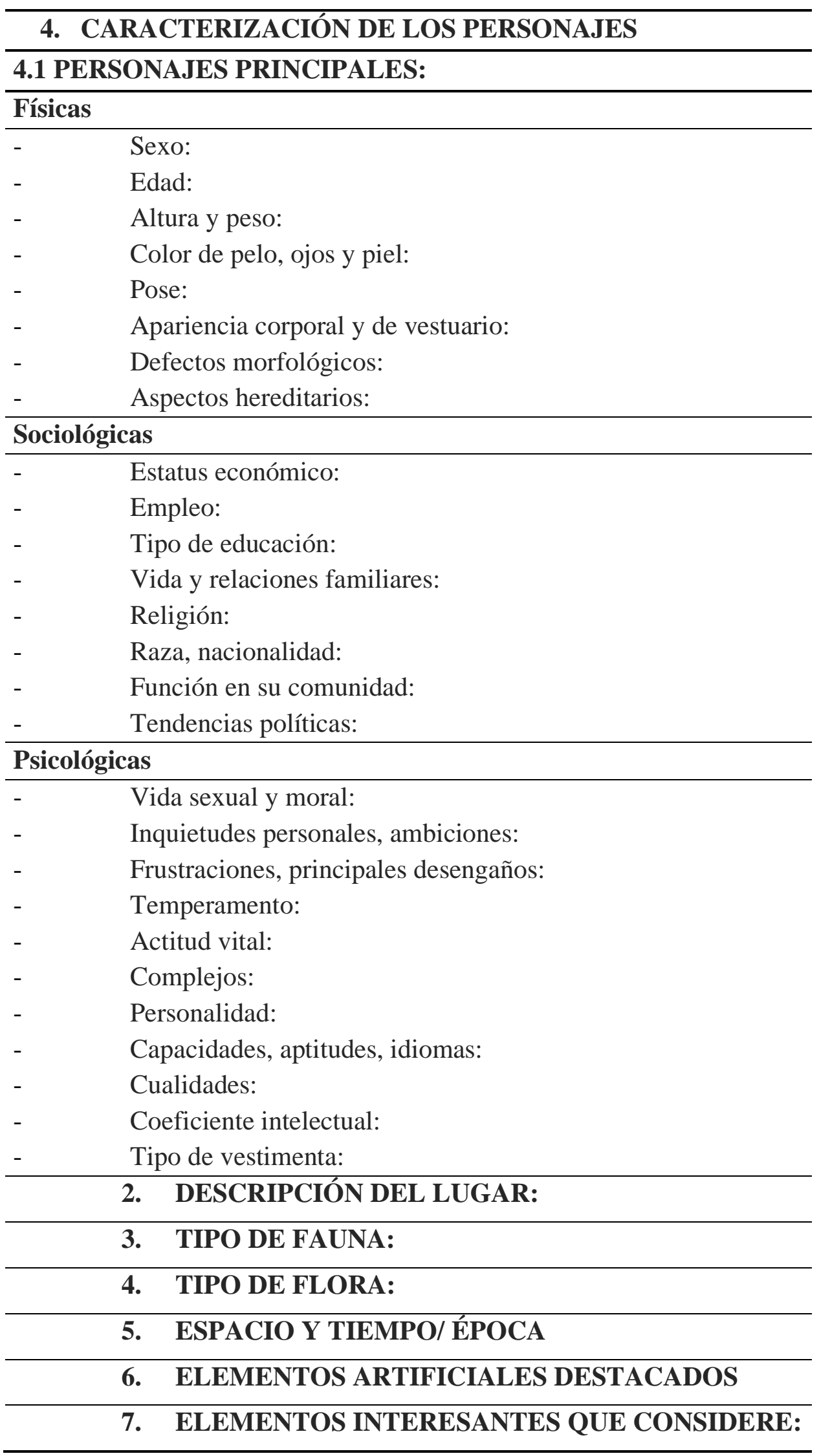

Fuente: Grupo de investigación IPCI, 2018 
Además, Wigan (2017), menciona "Cree su propio archivo o biblioteca de imágenes y utilice los motores de búsqueda de internet, su propia referencia fotográfica o de video, imágenes encontradas, bibliotecas. Todo esto proporcionará material de referencia visual que puede informar su trabajo o desencadenar asociaciones."

Así, además de estudio general previo que se desarrollo, en esta fase se realizó una investigación y documentación puntual de los aspectos de cada escena, en la cual se hizo un registro fotográfico de escenarios naturales y urbanos de los sitios de la ciudad donde se supone se desarrollaron los hechos, se tomaron fotografías históricas de fuentes de internet de páginas especializadas

\section{Selección de elementos narrativos}

Las decisiones plásticas que serán la primera impresión que el niño tenga de la leyenda, por lo que, usar los elementos visuales adecuados es clave para contar una historia, para ello es necesario tener claro el objetivo comunicacional de cada parte de la historia, es decir del hecho o suceso que se esta ilustrando.

Grove (2013), Una ilustración debe seguir ciertos parámetros y tener ciertas características para demostrar ser contundente y ser calificada como una buena ilustración. La comunicación, la relación entre el texto y la imagen, el factor emocional, el aura o su nivel de significación, la relación con contextos históricos y culturales, la creatividad, la continuidad, simbolismo, composición y la originalidad son algunos de los aspectos claves a la hora de desarrollar una ilustración.

Por lo cual, se pensó en escenas apropiadas para el espíritu de la historia que resulten sensibles al ritmo de las palabras y las oraciones. Cada uno de los elementos gráficos: forma, color, perspectiva, movimiento, luz, se eligieron y acoplaron de tal manera que se logró adherirse a la historia y ala intención comunicativa de cada una de las leyendas.

Para ello, se generaron fichas técnicas creadas a partir del estudio general de la leyenda, y de la narración. Observemos un ejemplo de como se realizó la selección de los elementos narrativos utilizados en el fragmento\#5 extraído de la leyenda "La Silla del Cementerio", y posterior el resultado de la elección de los elementos narrativos en relación al texto Figura 1.

“A partir de entonces, el alma de Jozef quedó destrozada... ¡Ahí se quedó!, inmóvil, no podía creer la magnitud de su desgracia. ¿Cómo seguir viviendo sin ella? La verdad es que con el transcurso de los meses no menguó su dolor, lo peor es que no podía sacar la imagen de Elizabeth de su mente, y así fue durante mucho tiempo. Sintiéndose muy desgraciado, el hombre pasaba día y noche abrazado a la lápida de su mujer; aferrado a las varillas que adornaban la tumba; dicen, que todos los días el extranjero acudía hasta la tumba de su amada, y alli permanecia horas y horas, "conversando" con ella, le leía libros de poemas, tocaba la guitarra y le cantaba. 


\section{Tabla 2}

Análisis Elementos Narrativos, fragmento "La Silla del Cementerio"

\begin{tabular}{|c|c|c|}
\hline \multicolumn{3}{|c|}{ ANÁLISIS FRAGMENTO\#5 “SILLA DEL CEMENTERIO" } \\
\hline $\begin{array}{l}\text { ELEMENTOS } \\
\text { NARRATIVOS }\end{array}$ & $\begin{array}{l}\text { ELEMENTO } \\
\text { EMPLEADOS }\end{array}$ & ANÁLISIS / CONCEPTUALIZACIÓN \\
\hline $\begin{array}{l}\text { Elementos } \\
\text { plásticos }\end{array}$ & $\begin{array}{l}\text { Tono } \\
\text { Forma } \\
\text { Perspectiva }\end{array}$ & $\begin{array}{l}\text { - A nivel general se usan formas curvas, } \\
\text { logrando un efecto emotivo en la ilustración } \\
\text { - Para el tono se usó una escala tonal azul, para } \\
\text { expresa el sentimiento de tristeza de la escena. } \\
\text { - Se eligió una perspectiva frontal que permite } \\
\text { visualizar todo lo que ocurre en la escena. } \\
\text { - La iluminación es poca ya que la escena se } \\
\text { desarrolla en el cementerio en la noche donde } \\
\text { la luz es escasa. }\end{array}$ \\
\hline $\begin{array}{l}\text { Elementos } \\
\text { compositivos }\end{array}$ & Encuadre & $\begin{array}{l}\text { - La carga visual se encuentra a lado derecho } \\
\text { donde está la tumba y el personaje principal. } \\
\text { - Se usa un plano general para poder observar } \\
\text { el lugar donde se desarrolla la escena. } \\
\text { - El encuadre permite descubrir la trayectoria } \\
\text { del pájaro que representa a Elizabeth. }\end{array}$ \\
\hline $\begin{array}{l}\text { Elementos } \\
\text { conceptuales }\end{array}$ & $\begin{array}{l}\text { Personajes } \\
\text { Escenarios }\end{array}$ & $\begin{array}{l}\text { Se usa como escenario principal el } \\
\text { cementerio, se usa un ambiente frío con la } \\
\text { cromática y la lluvia. Los objetos que se pueden } \\
\text { observar pertenecen al personaje y están } \\
\text { colocado de forma desordenada para } \\
\text { demostrar. } \\
\text { el caos que vive el personaje, en contraste a lo } \\
\text { que se podía observar en las primeras escenas } \\
\text { donde le personaje tenía el control sobre sus } \\
\text { pertenencias. Con respecto a la acción se pude } \\
\text { observar al personaje de rodillas, llorando lo } \\
\text { que demuestra la tristeza que consolida el tono } \\
\text { de la ilustración. }\end{array}$ \\
\hline
\end{tabular}

Fuente: Elaboración Propia

Así, a partir del ensamblaje de referencias (imágenes) se llega a la conceptualización; por un lado las imágenes recogidas en el proceso previo proporcionaron el material de referencia visual que, a su vez, permitieron realizar las asociaciones con el texto. 


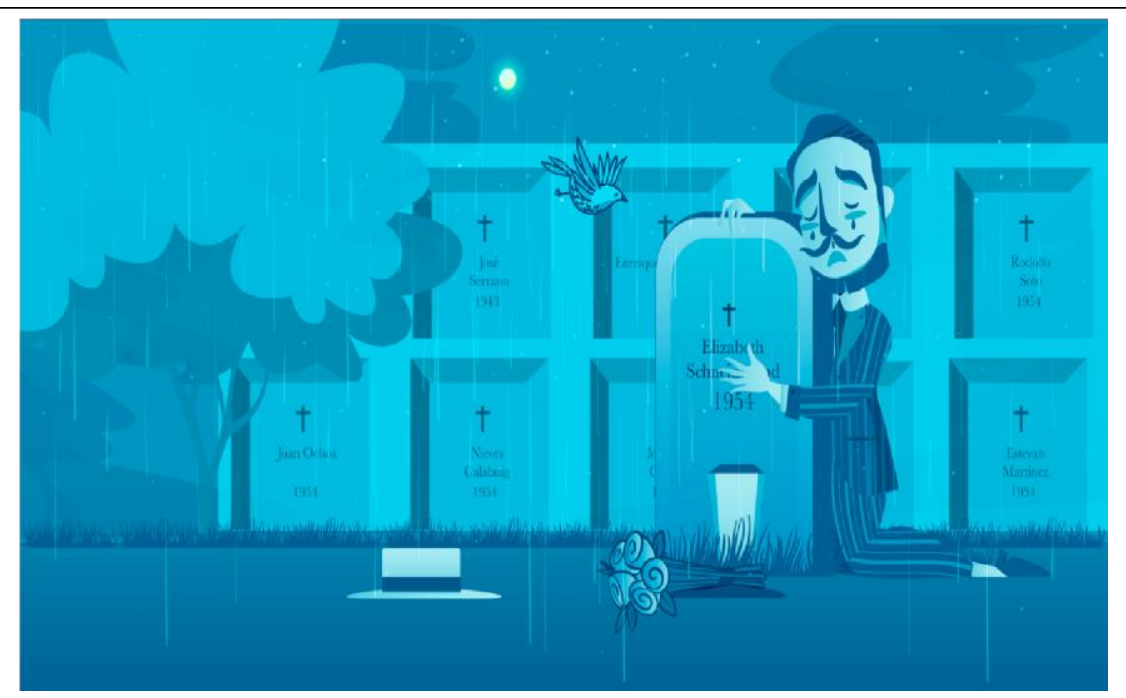

Figura 1. Ilustración del fragmento\#5 de la leyenda "La Silla del Cementerio".

Fuente: Elaboración Propia

\section{Resultados}

\section{Elaboración de las ilustraciones}

Sobre la producción de las ilustraciones, el ilustrador debe de ser cuidadoso en la elaboración de imágenes destinada a los niños. La ilustración, además de movilizar recursos artísticos, requiere de estrategias de creación y comunicación

En inicio, para elaborar las ilustraciones es preciso considerar las características del público para quien se ilustra, en este caso los niños y niñas de la ciudad de Riobamba. Por otro lado, la representación de los conceptos (hechos o suceso) apoyada en los elementos narrativos generaran ilustraciones contundentes. Además, a través de la aplicación de la técnica y la concepción del estilo se puede lograr una riqueza expresiva y dotar de significados a las imágenes.

\section{Elección de la técnica}

Antes de tomar las decisiones plásticas, se determinó el formato en la que se difundirá las leyendas. Considerando la aplicación y difusión de las ilustraciones, en productos y medios digitales respectivamente tales como: la animación, juegos interactivos, páginas web entre otros, se ha optado por la técnica digital, ya que además de ser idónea para este tipo de formatos permite la edición de la ilustración para adaptarla a diferentes necesidades. La ilustración de la Figura 2, que se observa a continuación fue realizada en el software de diseño Adobe Illustrator y posteriores se realizaron los acabados en el software de A. Photoshop. 


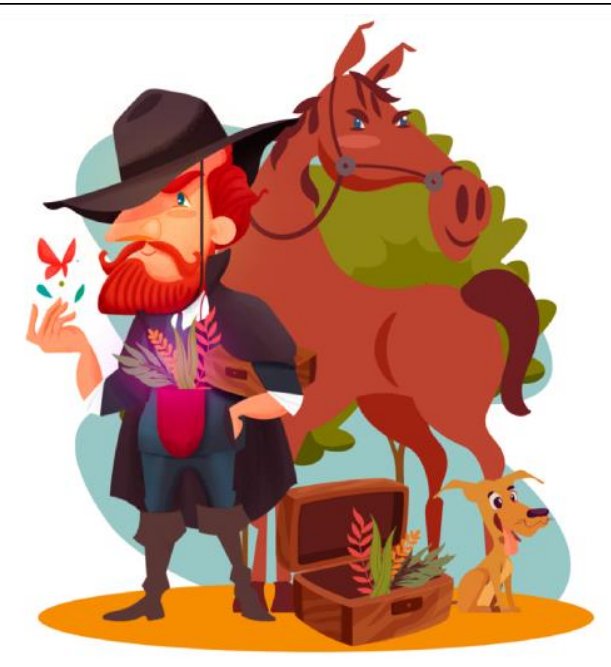

Figura 2, Personajes Principales "El Luterano" Fuente: Elaboración Propia

\section{Selección de Estilo}

Después de establecer el texto que se va a representar, los elementos que se van incluir y cómo se va llevar a cabo, se estableció la apariencia que va a manejar, para ello se consideraron algunos factores.

En primer lugar, menciona "La empatía como característica esencial del ser humano puede emplearse como medio fundamental al instante de contar una historia. Su aprovechamiento radica en puede ser manejada como una herramienta para el narrador". Por lo que, la determinación de un estilo conveniente para la ilustración depende principalmente del público que se está abordando, los niños.

Otro factor importante mencionar el grado de iconicidad de la imagen que se maneje.

Castillo (2012), dice "La iconicidad no es otra cosa que la mayor o menor concordancia entre el objeto representado (referente) y su representación (significante). Un dibujo puede asimilarse a un signo o a un icono, y su representación, su identificación e interpretación, marcan la cantidad y calidad de la información que nos llega con su observación. Así mismo, (Helmick, 1995) menciona, "Muchos concuerdan con que los gráficos realistas clarifican mejor la ilustración que gráficos simples o esquemáticos, por eso es recomendable manejar estilos gráficos que mantengan relación con elementos de la realidad. Sin embargo, esto no quiere decir que las ilustraciones sean copias exactas del referente real, sino que los dibujos deben guardar un grado de similitud lo suficientemente alto para que el niño sea capaz de reconocer la imagen de la que se habla en el texto.

En conjunción, al tratarse de un público infantil, se inclinó por un estilo simple, que se centró en lograr captar la esencia del representado, para que pueda ser reconocido fácilmente por el niño, usando un mínimo de trazos o rasgos para lograr un dibujo sencillo, también se aplico algunas técnicas del estilo caricaturesco que se caracteriza por 
la desproporción de rasgos con el objetivo de llamar la atención y divertir, logrando así generar empatía con el niño. Sumado a esto y basados en la experiencia de otros ilustradores, en relación al diseño de los personajes algunos sugieren usar ciertos rasgos que pueden resultar atractivos para los niños y que se identifican rápidamente con ellos.

Por ejemplo, García H. (2015) habla acerca de las características tipológicas de los personajes infantiles entre las que menciona:

- La estructura del cráneo suele ser mayor que la maxilar.

- La cabeza posee un tamaño más grande con respecto al cuerpo.

- Prevalece la línea de acción dinámica.

- Posee una apariencia frágil.

- Muestra líneas de flotación cóncavas representando buen ánimo, en donde piernas y brazos poseen apariencia robusta.

Así, se ha considerado estas recomendaciones para la representación de los personajes, seres, escenarios y objetos.

\section{Diseño de Personajes}

De acuerdo a Cámaras (2006), el personaje es quien conduce al público en el desarrollo de la historia. Así mismo, Lluch (2003), sostiene que por personajes entiende al intérprete del relato dotado de una serie de características que lo definen, que poseen una unidad y lo separan del resto, lo que a su vez respalda su comportamiento y relaciones que establece con otros personajes. Dichas actitudes son relativamente estables, pero pueden cambiar según el desarrollo de la historia.
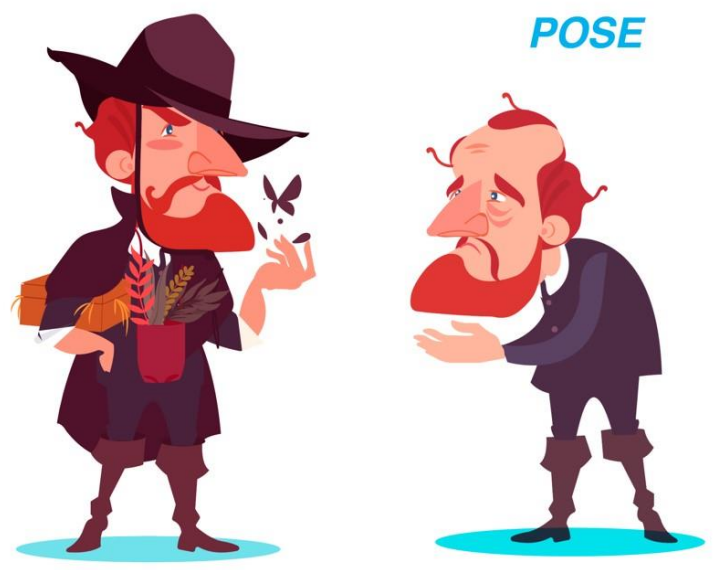

Figura 3. Poses Personaje "El Luterano" Fuente: Elaboración Propia

De estas dos visiones, el desarrollo de las ilustraciones partió principalmente del desarrollo de los personajes principales, quienes a través de rasgos como la pose (observe Figura 3), marcaron el tono de la ilustración, transportaron al niño a una época, través de 
su vestuario y hasta provocaron empatía al coincidir con el niño sobre sus intereses y valores. Por ello, previo al diseño del personaje, se realizaron fichas de los personajes principales y secundarios en la cuales, se incluyó características fisiológicas, sicológicas y sociológicas y otra información derivada del estudio general de la leyenda. Observe Figura 4

\section{Tabla 3}

Ficha del personaje "El Chuzalongo

\section{CARACTERÍSTICAS DEL PERSONAJE}

\section{Personaje: Chuzalongo}

3.2. Físicas $(\mathrm{V}, 2.3 .3 .2) a)$.

Sexo: Masculino

Edad: 50

Altura y peso: $112 \mathrm{~cm}-25 \mathrm{~kg}$

Color de pelo, ojos y piel: cabellera larga, ojos grandes.

Pose: de pie

Apariencia corporal: pequeño y robusto

Vestuario: indumentaria indígena de Chimborazo, poncho y sombrero

Defectos morfológicos: miembro viril de gran tamaño

Aspectos hereditarios: indígena

3.3. Sociológicas $(\mathrm{V}, 2$.3.3.2) b).

Estatus económico: ninguno

Empleo: ninguno

Tipo de educación: ninguno

Vida y relaciones familiares: ninguno

Religión: ninguno

Raza, nacionalidad: mestizo

Función en su comunidad: asustar, violar y matar

Tendencias políticas: ninguno

Diversiones, aficiones: pasear en el páramo

3.4. Psicológicas $(\mathrm{V}, 2$.3.3.2) $c$ ).

Vida sexual y moral: sexualmente activo

Inquietudes personales, ambiciones: mujeres

Frustraciones, principales desengaños: ninguna

Temperamento: alegre - colérico

Idiomas: español

Cualidades: ninguno

Coeficiente intelectual: bajo

Fuente: Grupo de investigación IPCI, 2018 


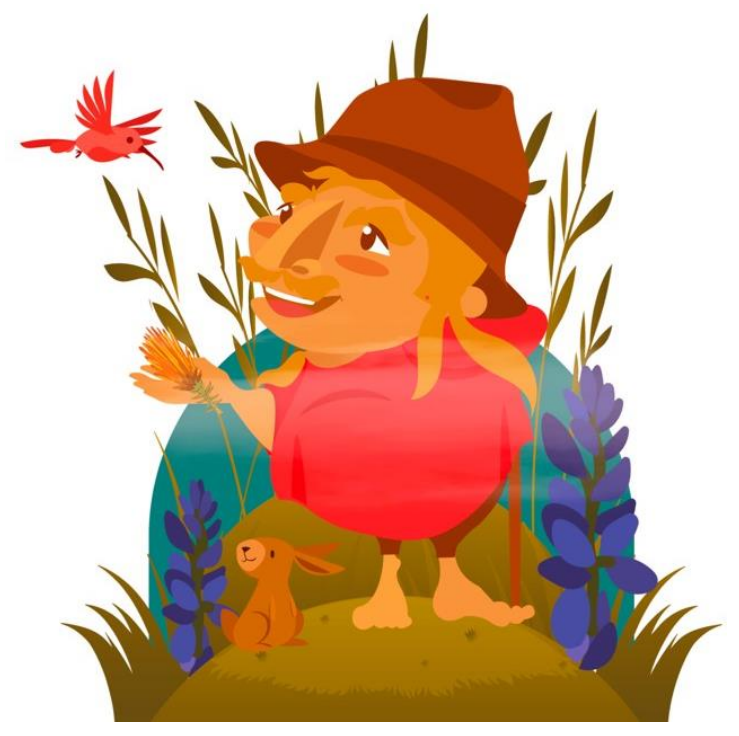

Figura 4. Diseño de Personaje "El Chuzalongo" Fuente: Elaboración Propia

\section{Escenarios.}

Citando a Fernández - Coca (2012), el escenario se define como el marco donde los personajes desarrollan los hechos. El escenario contribuye en gran manera para dar a entender las historias. Los escenarios se encuentran ubicados al fondo de las figuras, estos son representaciones visuales reales o ficticias. Estos pueden ser dibujados, estar elaborados de un tono plano o manejar componentes fotográficos etc. Así, para el desarrollo de los escenarios se tomó principalmente como referencias, escenarios reales obtenidos en la investigación a través del registro fotográfico y de fuentes bibliográficas especializadas, de las cuales se recrearon en las ilustraciones, tal como se observa en las Figura 5 y 6.

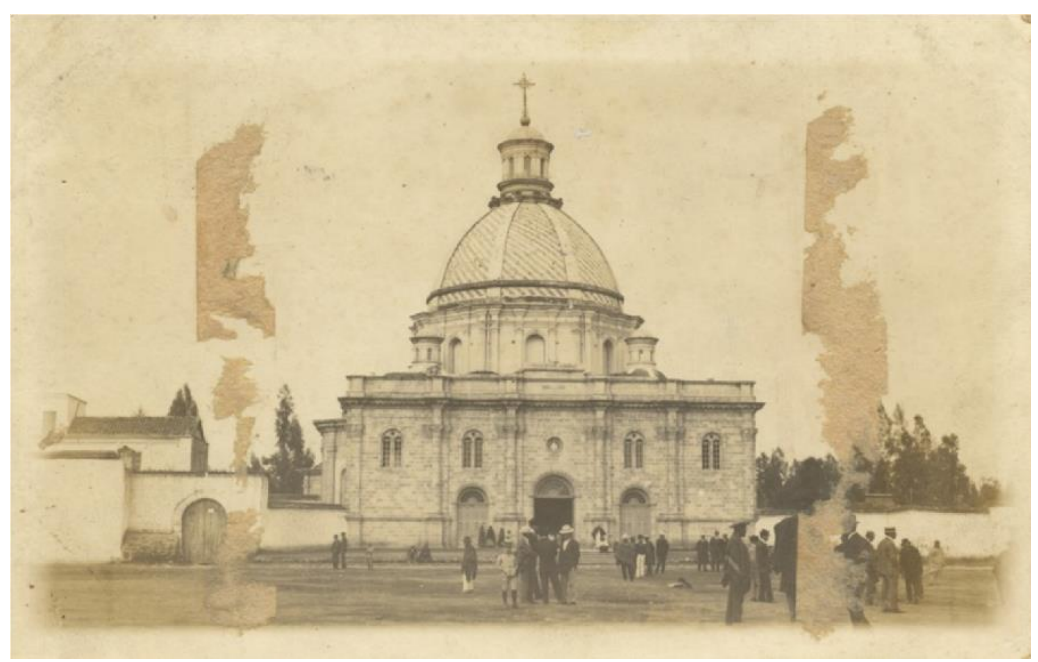

Figura 5, Basílica del Sagrado Corazón de Jesús, Riobamba Fuente: Fondo Fotográfico - Colección Estrada Ycaza 


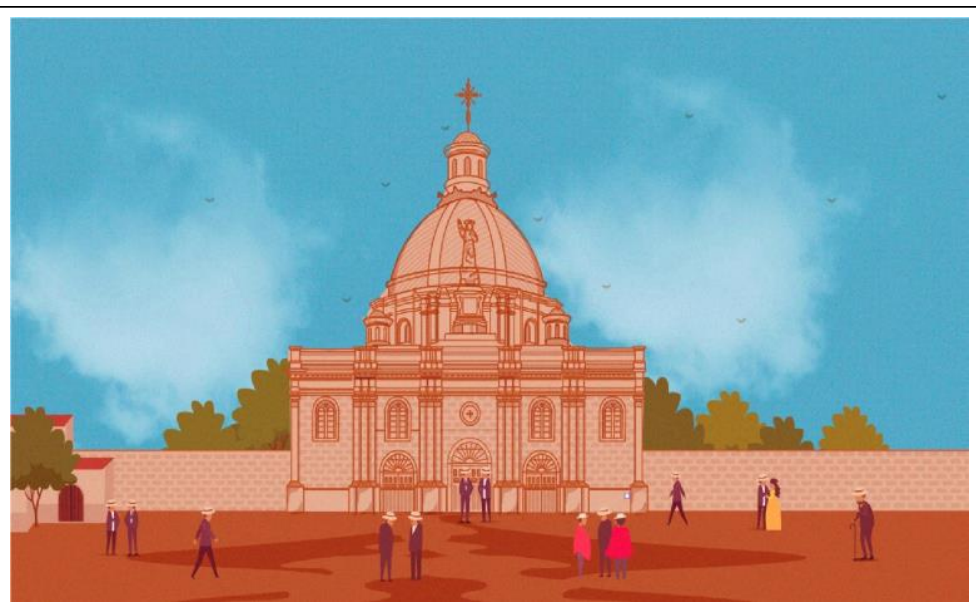

Figura 6, Escena\#1 "El Descabezado" Fuente: Elaboración Propia

\section{Conclusiones:}

- Las leyendas han sido una de las expresiones, en la forma oral o escrita, qué más van a utilizado los pueblos para tratar de explicar o dar respuesta en forma sencilla a fenómenos de difícil comprensión. Asimismo, han sido el medio para conservar parte de su historia y manifestar su ideología costumbres y ética, además de incluir en algunos casos, la descripción del medio que los rodea. En consecuencia, son una manifestación que requieren más allá de su lectura un análisis integral de todos los factores que intervienen en su elaboración y su contenido.

- A partir de la propuesta metodológica para ilustrar en 4 fases es posible recrear, visualizar e inventar el mundo real y ficticio; por ello, es plausible trazar rutas que favorezcan los procesos de creación de imagen. Contar con un método de trabajo permite al ilustrador estar a la altura de los retos de la profesión, toda vez que el método no constituye un obstáculo, sino por el contrario: da libertad, flexibilidad y seguridad al ilustrador, a la vez que le posibilita ampliar su conocimiento acerca del oficio de ilustrar y una mayor comprensión del mundo que lo rodea.

- La narrativa visual es clave al abordar temas culturales dirigidos a niños, ya que son atraídos por las imágenes que se les muestra más que por el texto, la ilustración ofrece una forma sencilla de abordar el tema. En estas ilustraciones se ven involucrados una serie de elementos para la narrativa, en donde cada uno tiene una misión específica, que al momento de integrarse logran formar una obra coherente, significativa y estética para el niño.

- Las decisiones artísticas son esenciales en el lenguaje visual ya que serán la primera impresión al niño acerca de la historia. Por lo tanto, es importante tener claras las posibilidades expresivas y connotativas, en cuanto a la elección de los recursos que se usan para la construcción de la ilustración, mismo que deben estar vinculados con el objetivo de la historia es decir del hecho o suceso que se esta ilustrando. - . Al analizar una serie de personajes para determinar su perfil construido con la intención de que estos transmitan temas de medio ambiente en 
nivel primario fue posible hallar características en común y otras relevantes para promover el aprendizaje en niños de primaria.

- Definir el perfil del personaje es realmente importante en el desarrollo de la leyenda puesto que con él se crea un vínculo con el grupo objetivo, que logra captar la atención del niño, empatizar y generar el deseo de querer memorizar transmitir las historias. No obstante, a pesar de esto, es claro que es difícil determinar exactamente cómo debe ser un personaje, tratándose de historias que no necesariamente abordan temáticas positivas, sino que relatan realidades dolorosas en donde es imposible lograr que el niño simpatice con el mismo, por lo que se debe tener claro el objetivo de las leyendas ilustradas, que más que encantar al niño a través de la gráfica, acompaña al texto tratando de e que este sea más digerible para el niño.

\section{Referencias Bibliográficas}

Archer B. (1995). "The Nature of Research", en Co - design. Interdisciplinary Journal of Design, January 1995, pp 6-13

Cámaras, S (2006). El dibujo animado. Barcelona España: Parramón Ediciones S.A.

Castillo-Vidal, Jesús. "Iconicidad en la ilustración para su representación en bases de datos documentales". Anuario ThinkEPI, 2012, v. 6, pp. 256-257.

Eco, H (1999). Preámbulo ¿sólo puede construirse el futuro sobre la memoria?, en Barret. Ducrocq, Francoise ( dir.) ¿Porque recordar?, pp 183-186, 207. Barcelona: Granica 2002

Erazo M., Calderón, F., Murillo, M. La Silla del Cementerio. Guardianes de la Memoria - Leyendas de Riobamba. 2019.

Erazo M., Calderón, F., Murillo, M., \& Ávalos, M. (2020). Educación interactiva: estrategia pedagógica para resignificar la identidad cultural y comprensión lectora de leyendas Riobambeñas. Ciencia Digital, 4(4), 44 - 64.

Fernández - Coca (2012), El arte de la ilustración, del concepto al éxito. Madrid: Ediciones Anaya Multimedia.

Führer (2014). Comunicación y Diseño. Obtenido de: http://fido.palermo.edu/servicios_dyc/blog/docentes/trabajos/31764_109748.pdf.

García, H. (2015), La narrativa visual en las ilustraciones de los libros educativos para el aprendizaje ambiental en nivel primario. [Tesis de Grado, Pontificia Universidad Rafael Landívar Repositorio Institucional 
Grove, J. (2013). Evaluating Illustration Aesthetically. Recuperado de http:// www.illustratorsillustrated.com/evaluati ng-illustration-aesthetically/ Menza, A.E.

Grupo de Invetsigación IPCI (2018). Riobamba. Escuela Superior Politécnica de Chimborazo

Helmick, R. (1995). Virtues of verisimilitude in design and art. Computers \& Graphics. Vol 19 (4).

Luciano M. \& Grimaldi E. (1998). Literatura infantil y desarrollo creativo. Santiago de Compostela: Griallibros.

Mastiposde, (2016). Obtenido de Mastipos de http://www.mastiposde.com/leyendas.html

Ministerio de Educación (2021) Obtenido de: https://educacion.gob.ec/curriculoeducacion-cultural-y-artistica/

Said, Edward (2001). Cultura, identidad e historia, en Schröder, Gerhart y Breuninger, Helga (comp.) Teoría de la cultura. Un mapa de la cuestión, pp. 37-53. Buenos Aires: Fondo de Cultura Económica.

Valenzuela, E. (2011). Leyenda: un recurso para el estudio la enseñanza de la geografía. Ecuador: Universidad Simón Bolívar.

Vernon, L. (1997). «Algunos aspectos que el ilustrador debe tener en cuenta en el proceso de creación de libros ilustrados para niños», en Ponencias del IV Sinposi Internacional Catalònia d'Il·lustració. Barcelona, Generalitat de Catalunya. Departament de Cultura (1997), p. 168.

Wigan, M. (2007). Secuential Images. Singapore: AVA Book Production Pte. Ltd.

Zamarripa, A. (2006), La psicología en la práctica guionista, Artículo Linda Seger, UNAM México, de punto F. Revista Digital Universitaria. Nación de publicaciones digitales. Disponible en: http://www.revista.unam.mx/vol.7/num9/art69/i nt69.

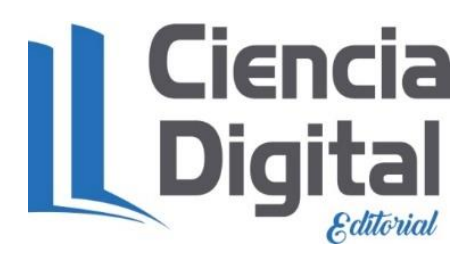




\section{PARA CITAR EL ARTÍCULO INDEXADO.}

Ramos Jiménez, R. B., Martínez Espinoza, E. F., Calderón Cruz, F. A., \& Erazo Rodríguez, M. E. (2021). Ilustración de las leyendas de la ciudad Riobamba, como estrategia para el fortalecimiento de la identidad cultural en la población infantil . Explorador Digital, 5(3), 139-155. https://doi.org/10.33262/exploradordigital.v5i3.1796

\section{$\lfloor$ Ciencia}

El artículo que se publica es de exclusiva responsabilidad de los autores y no necesariamente reflejan el pensamiento de la Revista Explorador Digital.

El artículo queda en propiedad de la revista y, por tanto, su publicación parcial y/o total en otro medio tiene que ser autorizado por el director de la Revista Explorador Digital.
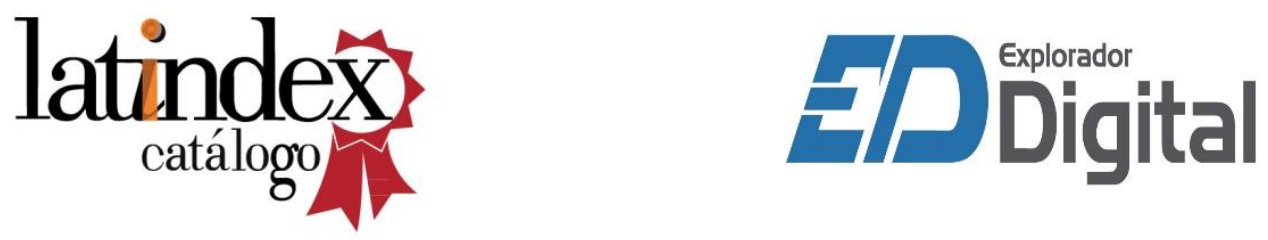